\title{
The age of 40, a cut-point for the change in the emotional responses of the brain; a voxel-based meta-analysis
}

\author{
Saif Aldeen AlRyalat* \\ School of Medicine, University of Jordan, 11942 Amman, Jordan
}

\begin{abstract}
The change of emotional responses of the brain with age is widely discussed in literature, some of these studies found the age of 40 to be pivotal in this regard. Taking the advantage of new functional neuroimaging techniques, we conducted a voxel-based meta-analysis to analyze the difference in brain activation during different emotional stimuli between individuals below the age of 40 years in one hand, and individuals above 40 years in the other hand. During different emotional stimuli, individuals above 40 years tend to activate areas that provide better self-control especially during sadness. In contrast, individuals below 40 years activate areas that cause loss of inhibition, especially, during anger.
\end{abstract}

\section{Introduction}

The association between age and emotion is well studied in details in several reviews and cross-sectional studies [1-4], almost all studies agreed that emotional reactions change with age, but still there is a controversy on the nature of this change, although most studies reported an increase in positive emotional reactions with age. A large study that analyzed data from Midlife in the United States (MIDUS) survey concluded that older adults report experiencing more positive and less negative emotional reactions than younger adults [2]. These optimistic findings suggest that as people get older, more pleasant emotions are being experienced.

The age of 40 was reported to be peculiar in several studies as several changes in the emotional responses occur at this age. Hare, a remarkable researcher in the field of psychology, reported that individuals less than 40 years of age react differently to stimuli, as they commit more crimes and spend more time in prison compared to older individuals [5]. Calder et al reported a significant decline in fear recognition and reaction after the age of 40 [6]. Memory, which is tightly associated with emotion, was reported to decline after the age of 40 [7].

The recently-developed functional imaging techniques; positron emission tomography (PET) scan and functional magnetic resonance imaging (fMRI), have improved our understanding of different emotional reactions by analyzing brain areas that are activated during these reactions [8]. Although these studies form a great method to study brain function, they usually depend on small sample population due to financial reasons, which is a drawback that might lead to low statistical power and sensitivity. We tried to overcome this issue by taking these studies together in a single meta-analysis that combines data from all of these studies to yield a high statistical power [9].

In the present voxel-based meta-analysis, we aim to study the peculiar age of 40 by analyzing brain activation during several emotional stimuli including; sadness, happiness, and anger and then interpreting these activations to understand how people less than 40 years of age differ from those over 40 years in their emotional responses.

\section{Methods}

Patient's data used in this study extracted from brainmap database (http://www.brainmap.org), details about studies included in this meta-analysis can be found in supplementary material. We analyzed all tested emotions (anger, anxiety, disgust, fear, happiness, and sadness), but only sadness, happiness, and anger had a sufficient data to be included in this meta-analysis and can provide an overview on emotional changes during life. The stimulus used to provoke the emotion of interest delivered by eye (pictures), or ear (sounds), or nose (odors). Criteria for patient's inclusion:

- Reported 3D coordinates either in Talairach or MNI systems.

- The implemented task should stimulate the emotion of interest in any mean (visual, hearing, smell ...etc).

- Voxels reported outside the cerebrum were excluded.

This study is a coordinate-based meta-analysis in which a systemic approach was adopted to gather relevant coordinates for peak activation during specific tasks for both sample populations; individuals less than 40 years and individuals more than 40 years of age, using functional neuroimaging techniques; fMRI and PET scan. We chose 3 main emotional stimuli; sadness, happiness, and anger, each of which was done simultaneously while undergoing a fMRI or PET scan.

This systemic approach started by using Sleuth brainmap software that is designed to extract peak activation coordinates from brainmap database that match given conditions [10]. 2 main conditions for the included studies were inputted in Sleuth; Aging (less than 40 and more than 40 years), and emotion experiment.

Correspondence to: Saif Aldeen AlRyalat, School of Medicine, University of Jordan, 11942 Amman, Jordan, Tel: +962-798914594, E-mail: Saifryalat@yahoo.com

Key words: age, emotion, sadness, happiness, anger, fMRI, PET scan

Received: September 11, 2016; Accepted: September 21, 2016; Published: September 24, 2016 
After the completion of coordinate's extraction for each population, a quantitative, coordinate-based activation likelihood estimation (ALE) analysis was done. ALE method is a statistical analysis that deals with $3 \mathrm{D}$ coordinates, this method assesses the probability of an event to occur at voxel level across studies by incorporating unthresholded data from each study, that are commonly reported in a standard stereotaxic space $(x, y, z)$, these $3 \mathrm{D}$ coordinate data are typically unfeasible to obtain solely [11]. The algorithm treats each coordinate of activation as a spatial probability. Subsequently, ALE maps are calculated by computing the convergence of activation probabilities for every voxel. A revised ALE algorithm was proposed and implemented in the Ginger ALE statistical software [12]. The new algorithm is statistically more robust as it treats the data using a random-effect approach, and models the uncertainty associated with a given coordinate. A P value of less than 0.0001 was considered significant (as recommended by Ginger ALE manual). Results after this analysis were given in clusters; each represents areas of significant activation across all studies in the Talairach system. Studies that originally listed coordinates in MNI space were transformed into Talairach space using icbm2tal [13] that is implemented in Ginger ALE.

Finally, results of the ALE analysis were represented onto an anatomical template designed for Talairach coordinates by Brainmap. org. In this regard, we utilized the Multi-Image Analysis software (Mango) that was also used to obtain the figures for each section [14].

\section{Results}

A total of 1632 subjects were included in this study, the details about the included sample including number of subjects, number of experiments (tasks), and the resulted number of active foci is listed in table 1. Details about activated areas coordinate and volumes found in supplementary material tables.

After ALE analysis for sadness, areas that were significantly activated in individuals less than 40 years of age were; left middle frontal gyrus, left lateral globus pallidu, left amygdala, left parahyppocampul gyrus, and bilateral inferior frontal gyri. Areas that were significantly activated in individuals more than 40 years of age were; left middle frontal gyrus, bilateral parahyppocampul gyri (BA 35,36), right inferior frontal, and left anterior cingulate gyrus (BA 32).

For happiness, areas that were significantly activated in individuals less than 40 years of age were; left amygdala, left fusiform gyrus, and right parahippocampal gyrus. Areas that were significantly activated in individuals more than 40 years of age were; left amygdala, right inferior parietal, right prefrontal, and left insula.

For anger, areas that were significantly activated in individuals less than 40 years of age were; left globus pallidus, left amygdala, bilateral prefrontal, and bilateral parahippocampul gyri. Areas that were significantly activated in individuals more than 40 years of age include; left globus pallidus, and left amygdala.

Table 1. Description of the included subjects.

\begin{tabular}{|l|c|c|c|c|}
\hline \multirow{3}{*}{ Sadness } & Age & $\begin{array}{c}\text { Number of } \\
\text { subjects }\end{array}$ & $\begin{array}{c}\text { Number of } \\
\text { experiments }\end{array}$ & $\begin{array}{c}\text { Number of active } \\
\text { foci }\end{array}$ \\
\cline { 2 - 5 } & $<40$ & 640 & 51 & 874 \\
\hline \multirow{2}{*}{ Happiness } & $>40$ & 417 & 31 & 518 \\
\cline { 2 - 5 } & $<40$ & 88 & 7 & 162 \\
\hline \multirow{2}{*}{ Anger } & $>40$ & 55 & 5 & 106 \\
\hline & $<40$ & 280 & 21 & 415 \\
\cline { 2 - 5 } & $>40$ & 152 & 9 & 193 \\
\hline
\end{tabular}

Figure 1 provides an overview on different brain areas that were significantly activated in the 2 populations.

\section{Discussion}

New brain functional imaging techniques led to more understanding of brain areas' functions. Now, each brain area has a proposed function that is predicted to take place upon the activation of this area. Correlating the pattern of activation during different emotional stimuli with the already-established brain area's function can lead researchers to find the strategy that is taking place during the performance of this task.

Generally, activation of the prefrontal area, which we found to be activated in both age groups, suggests emotional processing [15]. Previous research demonstrated that asymmetry in prefrontal activation is either due to emotional valence; as right prefrontal area is associated with positive emotions in contrast to the left prefrontal area which is associated with negative emotions [16], or due to emotional

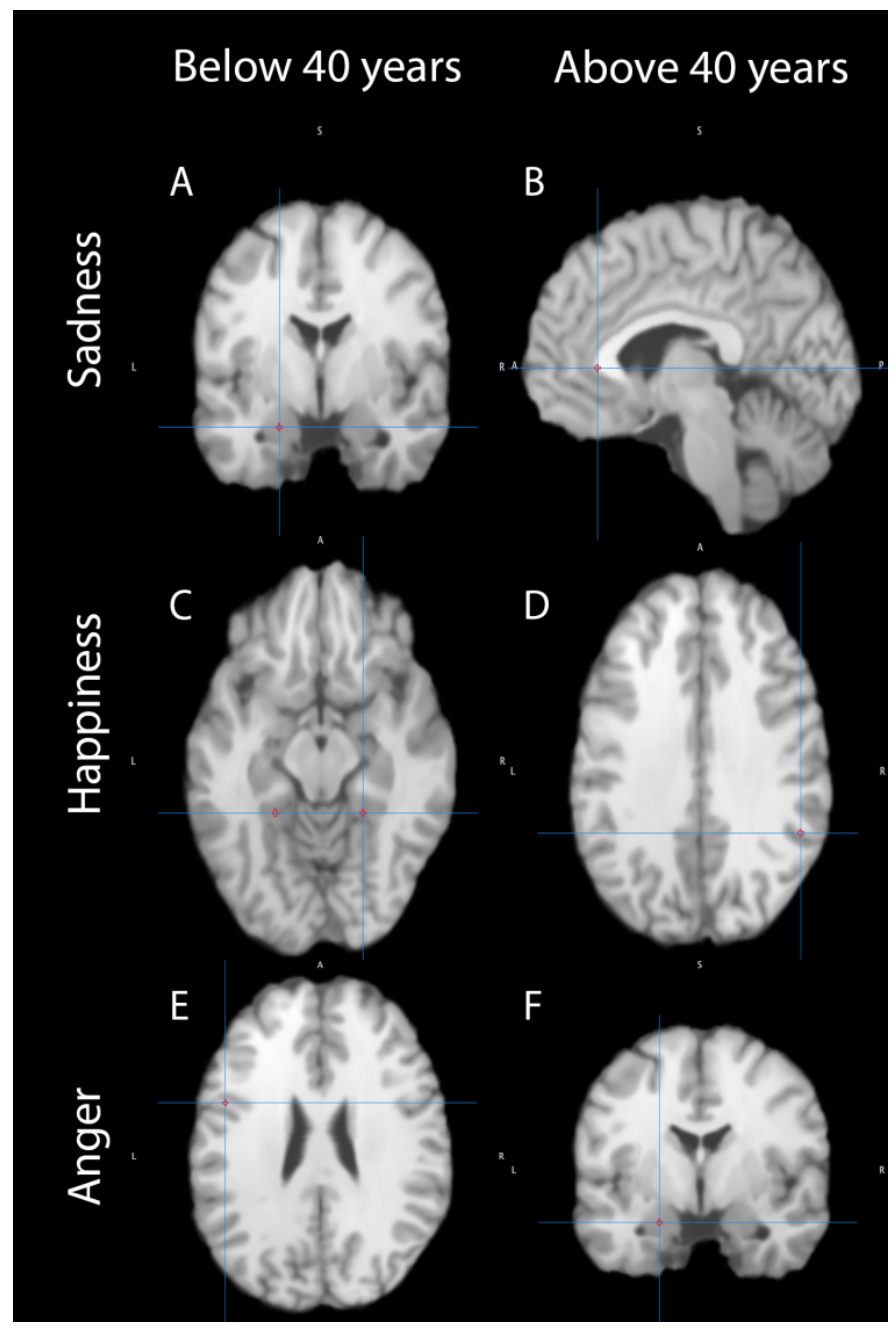

Figure 1. Different brain sections with the area significantly activated during the corresponding emotional response is marked. A: Left amygdala is activated in individuals below 40 years of age during sad stimulus. B: Anterior cingulate gyrus is activated in individuals above 40 years of age during sad stimulus. C: Bilateral parahippocampulgyri are activated in individuals below 40 years of age during happy stimulus. D: Inferior parietal lobule is activated in individuals above 40 years of age during happy stimulus. E: Prefrontal cortex is activated in individuals below 40 years of age during anger stimulus. F: Amygdala is activated in both age groups during anger stimulus. 
motivation [17]. Significant activation of left prefrontal gyrus in both age groups was noted in response to sad emotions. This area was recently found to be associated with failure of error inhibition and self-control [18]. It was also associated with an increase in anger and aggression [19]. Activity of parahippocampul gyri was also increased in both groups; this area was found to be associated with enhanced episodic memory function [20].

Anterior cingulate gyrus, an area that was activated significantly only in individuals over 40 years, is implicated in inhibition of negative thoughts and error recognition. It was also found to be impaired in patients with major depressive disorder [21]. Activation of this area is crucial for sad people in order to overcome these negative thoughts accompanying the experience of sadness.

Memory is closely associated with emotion, but this association is still not fully-understood. Our results showed that the amygdala, an area that is associated with disruption of working memory, is significantly activated in individuals below 40 years while experiencing any of the three emotional stimuli. Conversely, activation of the inferior frontal gyrus was noticed in those above 40 years of age. This area opposes the effect of amygdala's activation as it enhances working memory [22].

Regarding happiness, both groups showed significant left amygdala activation which is activated upon emotional reaction and results in disruption of working memory [22]. Individuals below 40 years of age showed significant activation of both the fusiform gyrus and right parahyppocampal gyrus. The former area is implicated in facial recognition and processing [23], whereas the latter area has a role in long-term episodic memory processing, as previously mentioned. In contrast, individuals above 40 years showed significant activation of the insula, an area that was proposed to monitor the autonomic responses to emotional stimuli and self-control [24]. They also activated the inferior parietal lobule, an area that was reported to be activated during self and others discrimination [25]. In addition, they significantly activated the right prefrontal activation, which is implicated in pleasure processing [16].

For anger, only 2 areas showed significant activation in individuals above the age of 40; the left globus pallidus and left amygdala. These 2 reegions were also significantly activated in individuals less than 40 years of age. Globus pallidus function in emotional regulation is still not well understood, although its dysfunction in social anxiety disorders implies its important regulatory function [26]. Individuals less than 40 years of age tend to activate thee prefrontal area, in addition to amygdala and globus pallidus. The prefrontal area is implicated in failure of error inhibition and self-control [18]. Parahippocampul gyri activation was also noticed in those individuals.

There are several limitations for the meta-analysis. First, we did not take into account the effect of gender discrepancy on brain activation strategy. Second, we also did not exclude individuals with certain comorbidities, as those individuals are minority that will not affect the end result of significant brain activation (due to the high threshold of the analysis).

\section{Conclusion}

According to the pattern of brain activation during sadness, individuals over 40 years of age activate areas that inhibit negative thoughts and enhance working memory compared to those less than 40 years of age. On the other hand, during happiness, working memory is expected to be impaired in both age groups, but individuals less than 40 years of age have an enhanced episodic memory, compared to those over 40 years who tend to activate other areas that are implicated in self-control. During anger, individuals less than 40 years of age activate areas that cause loss of inhibition and self-control.

\section{References}

1. Stevens D, Charman T, Blair RJ (2001) Recognition of emotion in facial expressions and vocal tones in children with psychopathic tendencies. J Genet Psychol 162: 201211. [Crossref]

2. Mroczek DK (2001) Age and emotion in adulthood. Current directions in psychological science 10: 87-90. [Crossref]

3. Mill A, Allik J, Realo A, Valk R (2009) Age-related differences in emotion recognition ability: a cross-sectional study. Emotion 9: 619-630. [Crossref]

4. Khawar R, Malik F, Maqsood S, Yasmin T, Habib S (2013) Age and gender differences in emotion recognition ability and intellectual functioning. Journal Behavioral Sciences 23: 53-71. [Crossref]

5. Hare RD, Hart SD (1993) Psychopathy, mental disorder, and crime. [Crossref]

6. Calder AJ, Keane J, Manly T, Sprengelmeyer R, Scott S, et al. (2003) Facial expression recognition across the adult life span. Neuropsychologia 41: 195-202. [Crossref]

7. Salthouse TA, Atkinson TM, Berish DE (2003) Executive functioning as a potential mediator of age-related cognitive decline in normal adults. Journal of Experimental Psychology: General 132: 566. [Crossref]

8. Robinson S, Moser E, Peper M (2009) fMRI of Emotion. FMRI Techniques and Protocols 411-456.

9. Phan KL, Wager T, Taylor SF, Liberzon I (2002) Functional neuroanatomy of emotion a meta-analysis of emotion activation studies in PET and fMRI. Neuroimage 16: 331348. [Crossref]

10. Fox PT, Laird AR, Fox SP, Fox PM, Uecker AM, et al. (2005) BrainMap taxonomy of experimental design: description and evaluation. Hum Brain Mapp 25: 185-198. [Crossref]

11. Salimi-Khorshidi G1, Smith SM, Keltner JR, Wager TD, Nichols TE (2009) Metaanalysis of neuroimaging data: a comparison of image-based and coordinate-based pooling of studies. Neuroimage 45: 810-823. [Crossref]

12. Eickhoff SB, Laird AR, Grefkes C, Wang LE, Zilles K, et al. (2009) Coordinate?based activation likelihood estimation meta?analysis of neuroimaging data: A random?effects approach based on empirical estimates of spatial uncertainty. Human brain mapping 30: 2907-2926. [Crossref]

13. Lancaster JL, Tordesillas-Gutiérrez D, Martinez M, Salinas F, Evans A, et al. (2007) Bias between MNI and Talairach coordinates analyzed using the ICBM-152 brain template. Human brain mapping 28: 1194-1205. [Crossref]

14. Lancaster JL, Laird AR, Eickhoff SB, Martinez MJ, Fox PM, et al. (2012) Automated regional behavioral analysis for human brain images. Front Neuroinform 6: 23 . [Crossref]

15. Diener C, Kuehner C, Brusniak W, Ubl B, Wessa M, et al. (2012) A metaanalysis of neurofunctional imaging studies of emotion and cognition in major depression. Neuroimage 61: 677-685. [Crossref]

16. Heller W (1990) The neuropsychology of emotion: Developmental patterns and implications for psychopathology. Psychological and biological approaches to emotion 1: 67-211. [Crossref]

17. Sutton SK, Davidson RJ (1997) Prefrontal brain asymmetry: A biological substrate of the behavioral approach and inhibition systems. Psychological Science 8: 204-210. [Crossref]

18. Heitzeg MM, Cope LM, Martz ME, Hardee JE, Zucker RA (2015) Brain activation to negative stimuli mediates a relationship between adolescent marijuana use and later emotional functioning. Developmental Cognitive Neuroscience 16: 71-83. [Crossref]

19. Harmon-Jones E, Sigelman J (2001) State anger and prefrontal brain activity: evidence that insult-related relative left-prefrontal activation is associated with experienced anger and aggression. Journal of personality and social psychology 80: 797. [Crossref]

20. Werner NS, Meindl T, Materne J, Engel RR, Huber D, et al. (2009) Functional MRI study of memory-related brain regions in patients with depressive disorder. $J$ Affect Disord 119: 124-131. [Crossref]

21. Allman JM, Hakeem A, Erwin JM, Nimchinsky E, Hof P (2001) The anterior cingulate cortex. The evolution of an interface between emotion and cognition. Ann N Y Acad Sci 935: 107-117. [Crossref] 
22. Dolcos F, Iordan AD, Kragel J, Stokes J, Campbell R, et al. (2013) Neural correlates of opposing effects of emotional distraction on working memory and episodic memory: an event-related FMRI investigation. Front Psychol 4: 293. [Crossref]

23. Geday J, Gjedde A, Boldsen AS, Kupers R (2003) Emotional valence modulates activity in the posterior fusiform gyrus and inferior medial prefrontal cortex in social perception. Neuroimage 18: 675-684. [Crossref]

24. Elliott R, Rubinsztein JS, Sahakian BJ, Dolan RJ (2002) The neural basis of mood- congruent processing biases in depression. Arch Gen Psychiatry 59: 597-604. [Crossref]

25. Uddin LQ, Molnar-Szakacs I, Zaidel E, Iacoboni M (2006) rTMS to the right inferior parietal lobule disrupts self-other discrimination. Social cognitive and affective neuroscience 1: 65-71. [Crossref]

26. Arnold Anteraper S, Triantafyllou C, Sawyer AT, Hofmann SG, Gabrieli JD, et al (2014) Hyper-connectivity of subcortical resting-state networks in social anxiety disorder. Brain connectivity 4: 81-90. [Crossref]

Copyright: (C2016 AlRyalat SA. This is an open-access article distributed under the terms of the Creative Commons Attribution License, which permits unrestricted use, distribution, and reproduction in any medium, provided the original author and source are credited. 